\title{
Toepasbaarheid van de Participatieve Aanpak Werkaanpassing bij verzuim ten gevolge van psychische werkbelasting
}

\author{
K. Jettinghoff • A. Venema • J.R. Anema • I.A. Steenstra
}

Samenvatting Dit artikel betreft een onderzoek naar de bruikbaarheid van de Participatieve Aanpak Werkaanpassing - een stappenplan dat, uitgevoerd door de werknemer met klachten, diens leidinggevende en een procesbegeleider, leidt tot een plan van aanpak voor werkaanpassing - bij het aanpakken van verzuim door psychische werkbelasting.

Een secundaire analyse is uitgevoerd op de plannen van aanpak en vragenlijstgegevens van werknemers met ziekteverzuim door lage-rugklachten om na te gaan (1) of de aanpak ook psychische belastingsknelpunten signaleert bij deze werknemers, en (2) of voor psychische belastingsknelpunten andere typen oplossingen worden aangedragen dan voor fysieke belastingsknelpunten.

Het blijkt dat bij ongeveer eenderde van de werknemers die verzuimden met lage-rugklachten in het plan van aanpak psychische belastingsknelpunten werden gesignaleerd. Deze werknemers ervaren hogere taakeisen, zitten minder goed in het werk en vinden het werk lichamelijk inspannender dan werknemers zonder gesignaleerde psychische knelpunten in hun plan van aanpak. Bij psychische belastingsknelpunten worden vaker oplossingen aangedragen gericht op het aanpassen van inrichting van het werk en de organisatie.

Op basis van deze resultaten concluderen we dat de Participatieve Aanpak Werkaanpassing zinvol ingezet

\footnotetext{
K. Jettinghoff $(\bowtie)$

Drs. K. Jettinghoff is junior onderzoeker en drs. A. Venema is onderzoeker bij TNO Kwaliteit van Leven te Hoofddorp; dr. J. R. Anema is bedrijfsarts, universitair docent, coördinator bij het VUmc, afdeling Sociale Geneeskunde te Amsterdam; en dr. I.A. Steenstra is senior onderzoeker bij het Academisch Medisch Centrum, Coronel Instituut voor Arbeid, Milieu en Gezondheid te Amsterdam.Correspondentieadres: TNO

Kwaliteit van Leven, t.a.v. K. Jettinghoff, Postbus 718, 2130

AS Hoofddorp. E-mail: k.jettinghoff@arbeid.tno.nl.
}

zou kunnen worden bij werknemers die psychische werkbelasting ervaren en een effectevaluatie plaats dient te vinden bij deze patiëntengroep.

Keywords psychische klachten · rugklachten . werkhervatting $\cdot$ werkaanpassingen $\cdot$ protocol Participatieve Aanpak Werkaanpassing

\section{Inleiding}

Er zijn aanwijzingen dat werkgerichte interventies (zoals het aanpassen van de werkplek, werktijden en takenpakket) een positief effect hebben op werkhervatting en de kans op arbeidsongeschiktheid reduceren. ${ }^{1-3}$ In de praktijk blijkt echter dat bij de begeleiding van zieke werknemers weinig aandacht wordt gegeven aan tijdige werkhervatting en de daarvoor (tijdelijk) benodigde werkaanpassingen. ${ }^{4,5}$

Bedrijfsartsen adviseren wel werkgerichte interventies bij werknemers die verzuimen met lichamelijke klachten, ${ }^{6}$ maar minder bij werknemers die verzuimen om psychische redenen en waarbij het verzuim werkgerelateerd is. ${ }^{7}$ En werkgevers vinden het vaak moeilijk om psychische werkbelasting te signaleren en bespreekbaar te maken, met verzuim door psychische werkbelasting om te gaan, en om aangepast werk te vinden. ${ }^{8}$

1. Met de Participatieve Aanpak Werkaanpassing worden ook psychische belastingsknelpunten gesignaleerd waarvoor gerichte oplossingen (werkaanpassingen) in het plan van aanpak worden opgenomen.

2. Psychische belastingsknelpunten die we aantreffen in de plannen van aanpak, zijn met name knelpunten op het gebied van werkdruk, 
Tabel 1 Overzicht stappenplan Participatieve Aanpak Werkaanpassing

\begin{tabular}{|c|c|}
\hline Stap & Acties \\
\hline \multirow[t]{4}{*}{ Stap 0} & Doorverwijzing door bedrijfsarts naar arboadviseur \\
\hline & Indien werknemer arbeidsrelevante klachten heeft \\
\hline & Indien werkaanpassingen nodig zijn om het werk weer te kunnen hervatten \\
\hline & Indien werknemer en werkgever actief mee willen werken \\
\hline \multirow[t]{2}{*}{ Stap 1} & Organisatie en voorbereiding door arboadviseur (binnen 1 week na verwijzing) \\
\hline & Neem contact op met werknemer en leidinggevende \\
\hline \multirow[t]{4}{*}{ Stap 2} & Inventarisatie knelpunten door arboadviseur, met werknemer en leidinggevende apart \\
\hline & Werkplekoriëntatie/inventarisatie van taken en werkzaamheden \\
\hline & Inventariseer en prioriteer knelpunten met werknemer \\
\hline & Inventariseer en prioriteer knelpunten met leidinggevende \\
\hline \multirow[t]{4}{*}{ Stap 3} & Inventarisatie werkaanpassingen door arboadviseur, met werknemer en werkgever samen \\
\hline & Bespreek geprioriteerde knelpunten \\
\hline & Bedenk werkaanpassingen \\
\hline & Neem besluit over werkaanpassingen en termijnen \\
\hline \multirow[t]{3}{*}{ Stap 4} & Voorbereiding werkaanpassingen en rapportage door arboadviseur (interventieduur stap $1 \mathrm{t} / \mathrm{m} 4$ twee weken) \\
\hline & Maak plan van aanpak/advies \\
\hline & Eindrapportage naar bedrijfsarts, leidinggevende en werknemer \\
\hline \multirow[t]{3}{*}{ Stap 5} & Begeleiding bij uitvoering werkaanpassingen door arboadviseur \\
\hline & Geef zo nodig voorlichting en instructie \\
\hline & Terugvalpreventie \\
\hline \multirow[t]{4}{*}{ Stap 6} & Controle en evaluatie door bedrijfsarts \\
\hline & Evalueer het plan van aanpak (na 1 maand) \\
\hline & Maak afspraken over de duur van tijdelijke werkaanpassingen \\
\hline & Bepaal wanneer een volgend (spreekuur)contact nodig is \\
\hline \multirow[t]{3}{*}{ Stap 7} & Bijstelling en continuering door bedrijfsarts \\
\hline & Breng verdere verbeteringen aan bij werkaanpassingen die nog niet voldoen \\
\hline & Keer terug naar eerdere stappen en verwijs zo nodig opnieuw naar de arboadviseur/bmw. \\
\hline
\end{tabular}

werksfeer, en knelpunten als gevolg van de persoonlijkheid van de werknemer.

3. Werknemers met psychische belastingsknelpunten in hun plan van aanpak geven in een vragenlijst aan hogere taakeisen te ervaren, minder goed in het werk te zitten, en hun werk lichamelijk inspannend te vinden (kruisvalidatie).

4. Bij psychische belastingsknelpunten worden met name het aanbieden van supervisie en ondersteuning en het aanpassen van werktijden als oplossingen aangedragen.

De Participatieve Aanpak Werkaanpassing is een instrument waarmee werkgever en werknemer, na verwijzing door de bedrijfsarts, onder begeleiding van een arboadviseur via een stapsgewijze aanpak komen tot signalering en bespreking van knelpunten op het werk en oplossingen daarvoor in de vorm van voorstellen tot aanpassing van het werk. Het resultaat is consensus over en betrokkenheid bij (a) een inventarisatie van knelpunten en bijbehorende oplossingen, (b) een plan van aanpak voor werkaanpassing, en (c) de uitvoering van het plan van aanpak (zie tabel 1). Doordat werknemer en werkgever een actieve inbreng hebben bij het opstellen van het advies en de daaruit volgende werkaanpassing, is de kans op acceptatie en implementatie van werkaanpassingen groter en wordt weerstand tegen veranderingen vermeden.

De Participatieve Aanpak Werkaanpassing is gebaseerd op onderzoek en ervaringen bij de begeleiding van individuele werknemers met rugklachten in Canada en aangepast voor de Nederlandse bedrijfsgezondheidszorg. ${ }^{9}{ }^{10}$ De methode is positief beoordeeld door werknemers die verzuimden wegens aspecifieke lage-rugklachten, en arboadviseurs die het protocol hebben doorlopen. ${ }^{10}$ Ook bleek dat werknemers bij wie het protocol was toegepast eerder weer volledig hervat waren dan werknemers die de gebruikelijke zorg krege$\mathrm{n},{ }^{6} \mathrm{en}$ dat het protocol een kosteneffectieve manier was om werknemers veilig terug te laten keren naar het werk. ${ }^{9}$

In dit artikel gaan we in op de vraag of de Participatieve Aanpak Werkaanpassing ook toepasbaar is bij verzuim waarbij werkgerelateerde psychische belasting een 
rol speelt. De aanname hierbij is dat bij een deel van de werknemers met lage-rugklachten ook psychische belastingsknelpunten meespelen. Uit eerder onderzoek blijkt dat er een relatie bestaat tussen psychosociale werkkenmerken en het optreden van lage-rugklachten, ${ }^{11,12}$ en dat een deel van de werknemers met rugklachten ook te maken heeft met bijkomende psychische problematiek. ${ }^{13}$

De vragen die wij in dit artikel willen beantwoorden zijn:

1. Worden met de Participatieve Aanpak Werkaanpassing ook psychische belastingsknelpunten opgespoord? Zo ja, welke?

2. Is er een verband tussen de in het plan van aanpak gesignaleerde psychische belastingsknelpunten en uit vragenlijstonderzoek bij dezelfde werknemers bekende psychosociale werkkenmerken?

3. Welke oplossingen worden gekozen bij psychische belastingsknelpunten?

\section{Methode}

Het onderzoek betreft secundaire (cross-sec-tionele) analyse van data afkomstig uit een randomized controlled trial naar de effectiviteit van het protocol Participatieve Aanpak Werkaanpassing bij werknemers die 2-6 weken verzuimden van hun werk vanwege aspecifieke lage-rugklachten. Werving van werknemers voor dit onderzoek verliep via 46 bedrijfsartsen met een populatie van 24.832 werknemers uit de sectoren gezondheidszorg, dienstverlening en industrie. ${ }^{6}$

Begeleiding door de bedrijfsarts en de arboadviseur (meestal een ergonoom) volgens het protocol is toegepast bij 96 werknemers. Bij 75 werknemers $(78 \%)$ is het protocol daadwerkelijk toegepast, is een plan van aanpak opgesteld door de arboadviseur, én heeft de werknemer een vragenlijst ingevuld. Om bovengenoemde onderzoeksvragen te beantwoorden zijn de plannen van aanpak en de vragenlijstgegevens van werknemers nader geanalyseerd. De werknemervragenlijst bevat onder meer vragen over psychosociale werkkenmerken (zoals taakeisen, regelmogelijkheden, sociale steun, en werkzekerheid), afkomstig uit de Nederlandse versie van de Job Content Questionnaire. ${ }^{14}$

De verschillende typen knelpunten en oplossingen die in het plan van aanpak worden genoemd, zijn geclassificeerd volgens het classificatieschema van Stapleton ${ }^{15}$ (zie tabel 3 en 5). Vervolgens is nagegaan of met het protocol ook psychische belastingsknelpunten - de knelpunten 'psychische werkbelasting' en/of 'stress' uit het classificatieschema van Stapleton - worden opgespoord, en zo ja, hoeveel en welke.
Om de vraag te beantwoorden of de aanwezigheid van psychische belastingsknelpunten in het plan van aanpak correspondeert met een maat voor psychische belasting in het werk, zijn gegevens uit het plan van aanpak gerelateerd aan vragenlijstgegevens van de respondenten (kruisvalidatie). Voor de groep respondenten met en de groep respondenten zonder psychische belastingsknelpunten in het plan van aanpak zijn gemiddelde scores berekend op enkele vragenlijstschalen en -vragen over psychische belasting in het werk. Middels t-toetsen is nagegaan of er verschillen zijn in gemiddelde scores tussen beide groepen.

Ten slotte is met behulp van $t$-toetsen nagegaan of er verschillen zijn in type oplossingen die aangedragen worden bij respondenten met respectievelijk zonder psychische belastingsknelpunten in hun plan van aanpak.

\section{Resultaten}

Van de 75 respondenten is $56 \%$ man, en de gemiddelde leeftijd is 43 jaar. De meeste respondenten werken in dienstverlenende beroepen $(61 \%$; met name gezondheidszorg), administratieve beroepen (19\%), en industriële beroepen (11\%) (zie tabel 2).

Worden met het protocol psychische belastingsknelpunten opgespoord?

In de plannen van aanpak die zijn opgesteld aan de hand van het protocol Participatieve Aanpak Werkaanpassing, zijn vooral knelpunten op het gebied van lichamelijke belasting in het werk (194 knelpunten bij 68 respondenten), en meubilair en hulpmiddelen (84 knelpunten bij 40 respondenten) gerapporteerd (zie tabel 3). Daarnaast bevatten de plannen van aanpak 31 psychische werkbelastingsknelpunten (mental workload) bij 19 van de 75 werknemers, en 24 knelpunten op het gebied van stress bij 16 van de 75 werknemers. Tezamen zijn 55 psychische belastingsknelpunten aangetroffen bij 28 van de 75 werknemers. Dit betreft vooral knelpunten op het gebied van werkdruk (zoals tijdsdruk, piekbelasting, personeelstekort), werksfeer (onder andere minder teamsaamhorigheid, verstoorde samenwerking, afwezigheid/wisseling van leiding), en persoonlijkheid van de werknemer (bijvoorbeeld perfectionisme, hoog verantwoordelijkheidsgevoel, moeilijk eigen grenzen aan kunnen geven).

Is er een verband tussen de in het plan van aanpak gesignaleerde psychische belastingsknelpunten en uit vragenlijstonderzoek bij dezelfde werknemers bekende psychosociale werkkenmerken?

Wanneer gekeken wordt naar de relatie van door werknemers gerapporteerde psychosociale werkkenmerken en de aanwezigheid van psychische 
Tabel 2 Kenmerken van de onderzoeksgroep

\begin{tabular}{|c|c|c|c|}
\hline Kenmerken & $\begin{array}{r}\text { Werknemers } \\
\text { zonderpsychischebelastingsknelpunten inhun } \\
\text { plan van aanpak }(\mathrm{n}=47)\end{array}$ & $\begin{array}{r}\text { Werknemers } \\
\text { metpsychischebelastingsknelpunten inhun } \\
\text { plan van } \operatorname{aanpak}(\mathrm{n}=28)\end{array}$ & $\begin{array}{r}\text { Totaal } \\
(\mathrm{n}=75)\end{array}$ \\
\hline \multicolumn{4}{|l|}{ Geslacht: } \\
\hline $\operatorname{man}$ & $57 \%$ & $54 \%$ & $56 \%$ \\
\hline vrouw & $43 \%$ & $46 \%$ & $44 \%$ \\
\hline Leeftijd (gemiddelde in jaren) & 43,6 & 42,9 & 43,3 \\
\hline \multicolumn{4}{|l|}{$\begin{array}{l}\text { Hoogste afgemaakte } \\
\text { opleiding: }\end{array}$} \\
\hline LO of geen opleiding & $2 \%$ & $7 \%$ & $4 \%$ \\
\hline LBO & $22 \%$ & $36 \%$ & $27 \%$ \\
\hline middelbaar/MBO & $44 \%$ & $32 \%$ & $40 \%$ \\
\hline voortgezet algemeen & $13 \%$ & $14 \%$ & $14 \%$ \\
\hline $\mathrm{HBO} /$ universiteit & $18 \%$ & $11 \%$ & $15 \%$ \\
\hline \multicolumn{4}{|l|}{$\begin{array}{l}\text { In welke categorie valt deze } \\
\text { functie: }\end{array}$} \\
\hline industrieel & $13 \%$ & $7 \%$ & $11 \%$ \\
\hline transport & $2 \%$ & $4 \%$ & $3 \%$ \\
\hline administratief & $15 \%$ & $25 \%$ & $19 \%$ \\
\hline commercieel & $2 \%$ & $4 \%$ & $3 \%$ \\
\hline dienstverlenend & $61 \%$ & $61 \%$ & $61 \%$ \\
\hline ander vakspecialistisch & $7 \%$ & $0 \%$ & $4 \%$ \\
\hline \multicolumn{4}{|l|}{$\begin{array}{l}\text { Huidige baan vast of tijdelijk } \\
\text { contract: }\end{array}$} \\
\hline vast dienstverband & $98 \%$ & $100 \%$ & $99 \%$ \\
\hline tijdelijk contract & $2 \%$ & $0 \%$ & $1 \%$ \\
\hline $\begin{array}{l}\text { Hoelang doet hij/zij huidig } \\
\text { werk (gemiddelde in jaren) }\end{array}$ & 12,0 & 13,8 & 12,7 \\
\hline
\end{tabular}

belastingsknelpunten in het plan van aanpak, dan is te zien dat bij respondenten die hogere taakeisen rapporteren, significant vaker een psychische belastingsknelpunt voorkomt in hun plan van aanpak (zie tabel 4). Respondenten met psychische belastingsknelpunten in hun plan van aanpak hebben een gemiddelde score van 13,9 op de schaal 'taakeisen' en respondenten zonder psychische belastingsknelpunten in hun plan van aanpak 12,9.

Ook blijkt dat bij respondenten die 'minder goed in hun werk zitten', vaker psychische belastingsknelpunten gesignaleerd worden. Van de respondenten met psychische belastingsknelpunten geeft 35,7\% aan goed in het werk te zitten. Bij respondenten zonder psychische belastingsknelpunten ligt dit percentage significant hoger, namelijk op $59,5 \%$.

Verder is er een significante relatie tussen de mate waarin men het werk lichamelijk inspannend vindt en de aanwezigheid van één of meer psychische belastingsknelpunten. Van de respondenten met psychische belastingsknelpunten vindt $75 \%$ het werk lichamelijk inspannend, en van respondenten zonder psychische belastingsknelpunten 47\%. Respondenten met psychische belastingsknelpunten vinden het werk ook vaker geestelijk inspannend dan respondenten zonder psychische belastingsknelpunten, maar dit verschil is niet significant.

Welke oplossingen worden gekozen bij psychische belastingsknelpunten?

Bij psychische belastingsknelpunten worden significant vaker oplossingen aangedragen gericht op het aanpassen van inrichting van het werk en organisatie, dan bij overige knelpunten (zie tabel 5). Dit geldt met name voor de oplossingen 'supervisie', 'ondersteuning' en 'werktijden'. Van de 77 genoemde oplossingen die worden aangedragen voor psychische belastingsknelpunten, betreffen 30 supervisie (39,0\%), terwijl slechts 28 van de 598 genoemde oplossingen die worden aangedragen voor overige knelpunten, supervisie betreffen (4,7\%). Ondersteuning wordt 13 van de 77 keer als oplossing aangedragen bij psychische belastingsknelpunten (16,9\%). Bij overige knelpunten vallen slechts 48 van de 598 oplossingen onder de categorie 'ondersteuning' (8,0\%). En 7 van de 77 oplossingen voor psychische belastingsknelpunten betreffen het aanpassen van de werktijden $(9,1 \%)$. Voor overige knelpunten is dit 18 van de 598 oplossingen $(3,2 \%)$. 
Tabel 3 Frequentie van verschillende typen knelpunten die zijn genoemd in het plan van aanpak

Totaal aantal keren genoemd

Type knelpunt:

1.Werkplekinrichting, meubilair en hulpmiddelen (workplace and equipment design).

a. werkplekinrichting (workstation design)

b. meubilair en hulpmiddelen (equipment design)

$\mathrm{n}$ dat type knelpunt is

$\begin{array}{rrrr}39 & 9,6 & 27 & 36 \\ 84 & 20,6 & 40 & 53\end{array}$

2. Inrichting van het werk en organisatie (work design and organisation):

a. werktijden (hours of work)

b. functieontwerp (job design)

c. training (training)

d. supervisie (supervision)

e. ondersteuning (use of support)

3. Omgeving (environment):

a. klimaat (climate)

4.Werkgerelateerde factoren (task related factor):

a. psychische werkbelasting (mental workload)

b. lichamelijke werkbelasting (physical workload)

c. stress (stress)

5. Anders (other fields)

5. Anders
Totaal

4

1,0

$\begin{array}{rrrr}4 & 1,0 & 4 & 5 \\ 23 & 5,7 & 18 & 24 \\ 2 & 0,5 & 1 & 1 \\ 1 & 0,3 & 1 & 1 \\ 0 & 0 & 0 & 0\end{array}$

5,7

Aantal werknemers

waarbij type knelpunt is genoemd

$\begin{array}{ll} & \% \\ 27 & 36 \\ 40 & 53\end{array}$

Tabel 4 Werkkenmerken van respondenten met en zonder psychische belastingsknelpunten in het plan van aanpak

Aanwezigheid knelpunt psychischewerkbelasting/stress

Werkkenmerken:

Plezier in werk

af en toe
vrij veel
heel veel

$\begin{array}{rrrr}31 & 7,6 & 19 & 25 \\ 194 & 47,7 & 68 & 91 \\ 24 & 5,9 & 16 & 21\end{array}$

$\begin{array}{llll}1 & 0,3 & 5 & 7\end{array}$

407

100

75

100
Taakeisen

Vaardigheidsmogelijkheden

Autonomie

Regelmogelijkheden

Sociale steun chef

Sociale steun collega's

Werkzekerheid

Tegenstrijdige opdrachten

Langdurige intensieve concentratie

Al met al zit ik op werk...

Werk lichamelijk inspannend

Werk geestelijk inspannend

${ }^{*} \mathrm{p}<0,05$.

${ }^{a}$ Naarmate de score op deze schalen hoger wordt ervaart men meer van deze psychosociale werkkenmerken. Bijvoorbeeld respondenten met een hoge score op de schaal 'taakeisen' ervaren veel/hoge takeisen en respondenten met een lage score op de schaal 'taakeisen' ervaren weinig/lage taakeisen. En respondenten met een hoge score op de schaal 'autonomie' ervaren veel autonomie in hun werk, terwijl respondenten met een lage score op de schaal 'autonomie' weinig autonomie in hun werk ervaren. 
Tabel 5 Overzicht van typen oplossingen die aangedragen worden bij psychische belastingsknelpunten en overige knelpunten in het plan van aanpak

\begin{tabular}{|c|c|c|c|c|c|}
\hline \multirow[b]{3}{*}{ Type oplossing: } & \multicolumn{3}{|c|}{$\begin{array}{r}\text { Overige knelpunten } \\
\text { (alle knelpunten, behalve } \\
\text { psychische werkbelasting en } \\
\text { stress) }\end{array}$} & \multicolumn{2}{|c|}{$\begin{array}{r}\text { Knelpunt } \\
\text { 'psychisch } \\
\text { werkbelasting/ } \\
\text { stress' }\end{array}$} \\
\hline & \multicolumn{5}{|c|}{$\mathrm{e}$} \\
\hline & $\mathrm{n}$ & $\%$ & $\mathrm{n}$ & $\%$ & \\
\hline \multicolumn{6}{|c|}{ 1.Werkplekinrichting, meubilair en hulpmiddelen (workplace and equipment design): } \\
\hline a. werkplekinrichting (workstation design) & 51 & 8,5 & 0 & 0 & $* *$ \\
\hline b. meubilair en hulpmiddelen (equipment design): & 206 & 34,4 & 3 & 3,9 & $* * *$ \\
\hline \multicolumn{6}{|c|}{ 2. Inrichting van het werk en organisatie (work design and organisation): } \\
\hline a. werktijden (hours of work) & 19 & 3,2 & 7 & 9,1 & * \\
\hline b. functieontwerp (job design) & 152 & 25,4 & 10 & 13,0 & $*$ \\
\hline c. training (training) & 79 & 13,2 & 9 & 11,7 & \\
\hline d. supervisie (supervision) & 28 & 4,7 & 30 & 39,0 & $* * *$ \\
\hline e. ondersteuning (use of support) & 48 & 8,0 & 13 & 16,9 & $*$ \\
\hline \multicolumn{6}{|l|}{ 3. Omgeving (environment): } \\
\hline a. klimaat (climate) & 2 & 0,3 & 0 & 0 & \\
\hline \multicolumn{6}{|l|}{ 4.Werkgerelateerde factoren (task related factor): } \\
\hline a. psychische werkbelasting (mental workload) & 0 & 0 & 1 & 1,3 & $* *$ \\
\hline b. lichamelijke werkbelasting (physical workload) & 1 & 0,2 & 0 & 0 & \\
\hline c. stress (stress) & 2 & 0,3 & 3 & 3,9 & $* * *$ \\
\hline 5. Anders (other fields) & 10 & 1,7 & 1 & 1,3 & \\
\hline Totaal & 598 & 100,0 & 77 & 100,0 & \\
\hline
\end{tabular}

${ }^{*} \mathrm{p}<0,05 ; * * \mathrm{p}<0,01 ; * * * \mathrm{p}<0,001$.

Onder supervisie vallen onder meer de oplossingen 'leidinggevende steunt of begeleidt werknemer', 'leidinggevende en werknemer onderhouden (regelmatig) contact of overleggen', en 'werknemer loopbaanbegeleiding aanbieden'. Ook worden hier organisatorische aspecten genoemd, zoals 'zorg voor continuïteit van beleid bij wisseling leidinggevende', '(duidelijkheid geven over de) uitbreiding van de afdeling en daaraan gekoppelde formatie', en 'bij reorganisatie rekening houden met planning op de werkvloer'.

Bij de overige knelpunten worden significant vaker oplossingen aangedragen gericht op het aanpassen van werkplekinrichting, meubilair en hulpmiddelen, dan bij psychische belastingsknelpunten. Het betreft met name oplossingen die vallen onder de categorie 'meubilair en hulpmiddelen'; bij overige knelpunten zijn 206 van de 598 oplossingen gericht op het aanpassen van meubilair en de aanschaf van hulpmiddelen $(34,4 \%)$, terwijl bij psychische belastingsknelpunten 3 van de 77 oplossingen valt onder de categorie 'meubilair en hulpmiddelen' $(3,9 \%)$.

\section{Beschouwing}

De resultaten van dit onderzoek laten zien dat met de Participatieve Aanpak Werkaanpassing naast fysieke knelpunten op het werk ook psychische belastingsknelpunten gesignaleerd en bespreekbaar worden en leiden tot concrete voorstellen voor oplossingen (werkaanpassingen) in een plan van aanpak. De psychische belastingsknelpunten van werknemers met rugklachten hadden met name betrekking op de werkdruk, de werksfeer en de persoonlijkheid van de werknemer. Daarnaast is aangetoond dat het aanwezig zijn van psychische belastingsknelpunten in het plan van aanpak gepaard gaat met enkele psychosociale werkkenmerken, te weten hogere taakeisen, het al met al minder goed in het werk zitten, en het werk als lichamelijk belastend ervaren. Voor psychische belastingsknelpunten worden met name oplossingen gezocht die zijn gericht op het aanpassen van de inrichting van het werk en de organisatie.

Een sterk punt van dit onderzoek is dat kwantitatieve gegevens over psychosociale werkkenmerken en kwalitatieve gegevens uit de plannen van aanpak zijn gecombineerd. Daarnaast maakt het feit dat het in dit onderzoek primair werknemers met rugklachten betrof en het hele onderzoek vanuit een 'fysieke' invalshoek is opgezet, de resultaten des te sterker. Omdat het hier werknemers betreft die verzuimen vanwege lichamelijke klachten (lage rug) is het te verwachten dat betrokkenen zich met name richten op lichamelijke knelpunten in het werk. Toch blijkt bij toepassing van het protocol bij medewerkers die verzuimen met lage-rugklachten dat ook 
psychische belastingsknelpunten besproken worden en dat deze leiden tot oplossingen in een plan van aanpak.

Er zijn echter ook een aantal kanttekeningen bij deze analyse te plaatsen:

1. Het betreft een secundaire analyse op een bestaand databestand over werknemers met rugklachten. Het was niet mogelijk om met de beschikbare data de effectiviteit van de oplossingen voor de psychische belastingsknelpunten nader te onderzoeken. Een gerandomiseerd gecontroleerd onderzoek specifiek gericht op werknemers die verzuimen met psychische klachten is dan ook gewenst.

2. Door de onderzoekers zijn bepaalde keuzes gemaakt omtrent de classificatie van de knelpunten en oplossingen. Het is mogelijk dat andere onderzoekers hierin andere keuzes zouden maken.

3. Er kan niet worden uitgesloten dat er - ondanks de relatief hoge respons $(78 \%)$ - een selectie heeft plaatsgevonden van gemotiveerde deelnemers (werknemers, arboadviseurs en werkgevers).

Ondanks bovengenoemde kanttekeningen komt uit deze analyse naar voren dat de Participatieve Aanpak Werkaanpassing bruikbaar lijkt te zijn bij het signaleren en bespreekbaar maken van psychische werkbelasting en werkaanpassingen gericht op het verminderen hiervan. Er is een prospectieve studie nodig om de effectiviteit van het protocol bij psychische belasting (en daarmee samenhangend verzuim door psychische klachten) vast te stellen in termen van reductie in psychische belastingsknelpunten en -klachten, en snellere werkhervatting.

Dit artikel is geschreven in het kader van het TNO doelfinancieringsprogramma 'Arbeid en Gezondheid' dat uitgevoerd wordt in samenwerking met het Ministerie van VWS.

\section{Literatuur}

1. Cuelenaere B, Giezen AM van der, Veerman TJ. Werkhervatting na rugklachten: langdurig zieke werknemers twee jaar gevolgd: eindrapport Nederlandse studie. Zoetermeer: College van Toezicht Sociale Verzekeringen (CTSV), 1999.

2. Blonk RWB, Lagerveld SE. Preventie Psychische Arbeidsongeschiktheid bij Zelfstandig ondernemers (PPAZ): resultaten van een gecontroleerd effectonderzoek. Hoofddorp: TNO Arbeid, 2003.

3. Anema JR, Cuelenaere B, Beek J van der. The effectiveness of ergonomic interventions on return to work after low back pain: a prospective two year cohort study in six countries on low back pain patients sick listed for 3-4 months. Occup Environ Med 2004; 61: 289-294.

4. Loisel P, Gosselin L, Durand P, et al. Implementation of a participatory ergonomics program in the rehabilitation of workers suffering from sub acute back pain. Appl Ergon 2001; 32: 53-60.

5. Scheel IB, Hagen KB, Herrin J, Oxman AD. A randomized controlled trial of two strategies to implement active sick leave for patients with low back pain. Spine 2002; 27: 561-566.

6. Anema A. Low back pain, workplace intervention \& return-towork [proefschrift]. Hoofddorp: TNO Arbeid, 2004.

7. Nieuwenhuijsen K. Employees with common mental disorders: from diagnosis to return to work [proefschrift]. Amsterdam: UvA, 2004.

8. Heuvel F van, Amstel R van, Jettinghoff K, et al. Evaluatie van de leidraad 'Aanpak verzuim om psychische redenen' in de Thuiszorg en GGZ. Hoofddorp: TNO Arbeid, 2004.

9. Steenstra IA. Back pain management in Dutch occupational health care [proefschrift]. Hoofddorp: TNO Arbeid, 2004.

10. Anema JR, Steenstra IA, Urlings IJ, et al. Participatory ergonomics as a return-to-work intervention: a future challenge? Am J Ind Med 2003; 44: 273-281.

11. Hoogendoorn WE, Poppel MNM van, Bongers PM. Systematic review of psychosocial factors at work and private life as risk factors for back pain. Spine 2000; 25(16): 2114-2125.

12. Hoogendoorn WE, Bongers PM, Vet HCW de. Psychosocial work characteristics and psychological strain in relation to low-back pain. Scand J Work Environ Health 2001; 27(4): 258-267.

13. Giezen AM van der, Veerman TJ, Prins, R. Werkhervatting na rugklachten: drie maanden in de Ziektewet: ervaringen van werknemers en hun bedrijfsartsen. Deelrapport 2. Zoetermeer: College van Toezicht Sociale Verzekeringen (CTSV), 1996.

14. Karasek R, Brisson C, Kawakami N, et al. The Job Content Questionnaire (JCQ): an instrument for internationally comparative assessments of psychosocial job characteristics. J Occup Health Psychol 1998; 3(4): 322-355.

Stapleton C,editor. Classification scheme. In: Ergonomics Abstracts Vol. 32. London: Taylor \& Francis Ltd, 2000, pp. i-vii. 